\title{
Management of Inverter-based Distributed Energy Resources for Providing Voltage Regulation Support in Islanded Operation of Low Voltage Networks
}

\author{
Mustafa Alparslan Zehir \\ Department of Electrical \\ Engineering \\ ITU - Istanbul Technical \\ University \\ Istanbul, Turkey \\ zehirm@itu.edu.tr \\ Riccardo Lazzari \\ Materials and Generation \\ Technologies Department \\ RSE - Ricerca sul Sistema \\ Energetico \\ Milan, Italy \\ riccardo.Lazzari@rse-web.it
}

\author{
Antonio Barbosa \\ Centre of Power and Energy \\ Systems \\ INESC TEC - Institute for \\ Systems and Computer \\ Engineering, Technology and \\ Science \\ Porto, Portugal \\ antonio.barbosa@inesctec.pt \\ Maurizio Verga \\ Materials and Generation \\ Technologies Department \\ RSE - Ricerca sul Sistema \\ Energetico \\ Milan, Italy \\ maurizio.verga@rse-web.it \\ Filipe Joel Soares \\ Centre of Power and Energy \\ Systems \\ INESC TEC - Institute for \\ Systems and Computer \\ Engineering, Technology and \\ Science \\ Porto, Portugal \\ filipe.j.soares@inesctec.pt
}

\author{
Carlo Sandroni \\ Materials and Generation \\ Technologies Department \\ RSE - Ricerca sul Sistema \\ Energetico \\ Milan, Italy \\ carlo.sandroni@rse-web.it
}

Mustafa Bagryianik

Department of Electrical

Engineering

ITU - Istanbul Technical University

Istanbul, Turkey

bagriy@itu.edu.tr

Aydogan Ozdemir

Department of Electrical Engineering

ITU - Istanbul Technical University

Istanbul, Turkey

ozdemiraydo@itu.edu.tr
Luigi Pellegrino

Materials and Generation

Technologies Department

RSE - Ricerca sul Sistema

Energetico

Milan, Italy

luigi.pellegrino@rse-web.it

Unal Kucuk

MAKEL Companies Group

Istanbul, Turkey

unal.kucuk@makel.com.tr

\begin{abstract}
Growing number of inverter-based distributed energy resources (DERs) and sensitive loads increase the need for coordinated power management activities in islanded operation of microgrids. Especially low voltage networks have low inertia and high $R / X$ ratio, causing instability due to fluctuations in distributed generation (DG) and local voltage problems in islanded operation. This study investigates management of DERs that operate in current mode for providing voltage regulation support to master unit(s) in islanded operation of microgrids. A special focus was set on local voltage issues in low voltage (LV) network feeders. Field experiments in a large test facility highlighted management accuracy and corrective impact potential of DERs connected to different parts of a feeder.
\end{abstract}

[1] Index Terms-Distributed energy resources, Islanded operation, Low voltage networks, Microgrids, Power management.

\section{INTRODUCTION}

Both the number and the capacity of microgrids and inverter-based distributed energy resources (DERs) have been growing all over the world because of their technical and economic benefits. A comprehensive study report indicates that, distributed battery storage is expected to grow rapidly in the next ten years [1]. According to the same report, operational microgrid power capacity in the US is $1.2 \mathrm{GW}$ as of 2014 , most of which are below $500 \mathrm{~kW}$. However, most of these applications are either military installations or university and research center belongings comprising medium voltage and low voltage networks. In the near future, the projections for microgrid deployments are expected to cover commercial and public areas as well as rural communities that are currently without electricity.

Rural microgrids are islanded systems whose total installed capacity are usually less than $100 \mathrm{~kW}$ and operating voltages are below $1 \mathrm{kV}$ [2]. Photovoltaic (PV) panels are widely used in these networks together with energy storage systems (ESS). The cables and lines in rural microgrids have small cross sectional areas with high $\mathrm{R} / \mathrm{X}$ ratios. DERs can provide voltage support in distribution networks through active or reactive power management [3]. In low voltage networks, due to dominant resistive character of the lines, active power flow has more dominant impact on voltage, compared to reactive power flow. [4]. 
Islanded networks comprise devices with low inertia and voltage sources with steady state output errors with the absence of the utility [5]. In islanded operation, one master unit -also called as grid forming unit- (single-master operation) or several master units (multi-master operation) maintain the voltage and the frequency by filling supply/demand gap [6,7]. The other power suppliers are grid following units (current source inverters) with the potential of providing support [8]. Most of these units in today's system are inverter-based. Inverter-based microgrids have control functions such as regulating the voltage at the output of each asset and keep each DERs' power value inside operational limits by sharing the load in islanded operation [9]. Voltage problems are more severe in islanded operation, compared to grid-connected operation due to high line impedances and primary control steady state errors [10].

Primary control may not be fully successful at maintaining voltage and frequency at their rated values [11]. Therefore secondary control using grid following DERs, is required to reduce steady state error of primary control in voltage amplitude restoration [12-13]. Secondary control was conventionally centralized, requiring complex communication networks and high computation times but showing low reliability. However, distributed cooperative control has become the spotlight of researchers due to their less communication and computation requirements, high reliability and flexibility [14].

Secondary control outputs should be limited to prevent violation of operational limits and power injection or absorption capability of the used units. [15] investigates cooperative control in islanded microgrids with secondary control using diesel generators. However DG units with mechanical auxiliary (such as pumps and shafts) and may not be capable of responding sufficiently fast to stabilize the system effectively [16]. Energy storage systems (ESS) can be preferred to overcome this problem. It should be noted that the use of ESS for secondary control is limited due to their limited storage capacities [16]. Coordinated control of several devices can overcome this problem.

Energy storage units can be used to meet the peaks in demand, to mitigate short disturbances, and to ride-through the outages until backup generators respond. They store energy during normal operation period to supply the grid during high loading periods [17]. Energy storage units can also play a crucial role in islanded systems by maintaining stable supply following the changes in local generation and demand [18]. In the islanded mode, energy storage assets can be used for a number of purposes such as power quality, stability and quick response to transients [10].

Studies in the literature are mainly based on simulations or compact grids comprising closely located devices in a small test bed, mostly neglecting the impact of control infrastructures in the field [4]. Moreover, islanded operation studies mostly include a diesel generator or a combined heat and power (CHP) unit [19]. Furthermore, the studies usually consider only islanded operation, without comparing the observed values with of grid-connected operation.

This study presents voltage regulation support by grid following batteries in islanded operation of low voltage networks with particular focus on local voltage problems. Field tests were conducted to quantify the impact of corrective actions on master unit bus voltage as well as on grid-following units' bus voltages. The results are compared with the values that are observed in grid-connected operation of the same units.

Section 2 has the details of the methodology, while section 3 includes field tests with the results. The last section discusses the findings and concludes the paper.

\section{INDICATORS FOR SUPPORTIVE DER POWER MANAGEMENT IN ISLANDED OPERATION}

The main indicators for secondary voltage regulation support through active power management in islanded operation are described in this section.

\section{A. Grid-Forming Unit Bus Voltage Sensitivity for Different Power Output Levels}

The terminal voltage of the device that is in voltage source mode strongly depends on its power output in islanded operation. The sensitivity of the voltage output of a master unit can be obtained by changing the loading of the device. Based on the measured quantities such as active power and voltage magnitude, a voltage/power curve highlighting the need for secondary voltage regulation support at different loading levels can be plotted. This curve represents the sensitivity of terminal voltage to changes in load. The slope of the curve $\left(v_{\text {sens }}\right)$ can be calculated using equation (1).

$$
v_{\text {sens }}=\frac{d V}{d P}
$$

In (1), $d V$ is the derivative of terminal voltage according to a change in output power $(d P)$. Character of loads (constant impedance, constant current or constant power) in the system can influence the shape of the slope. Since in small isolated low voltage distribution networks the loads are rather constant impedance, the curve is mostly linear.

\section{B. Management Accuracy of Grid Following Units}

DERs to provide secondary voltage regulation support through active power management need to be tested for management accuracy $\left(M_{a c c}\right)$. It is simply defined as the ratio of the output voltage $\left(P_{\text {output }}\right)$ to the set value $\left(P_{\text {desired }}\right)$ as given in (2).

$$
M_{\text {acc }}=\frac{P_{\text {output }}}{P_{\text {desired }}} \times 100
$$

The control error can be due to device and inverter nature, mechanical auxiliary (such as in disesel generator and combined heat and power units) and may vary from device to device. Moreover, new control approaches that are embedded into existing inverters may change the error ratings. Control approaches like PID can be applied with feedback from the utility side of the inverters to reduce the control error and to improve management accuracy. 


\section{Corrective Impact on Device Bus Voltage}

Voltage improvement impact $\left(v_{i m p}\right)$ of a managed device on its own bus can be evaluated using equation (3).

$$
v_{\text {imp }}=\frac{V_{\text {after }}-V_{\text {before }}}{V_{\text {nominal }}} \times 100
$$

In (3), $V_{\text {before }}$ and $V_{\text {after }}$ are the measured voltage values of a device bus before and after a power set point change, respectively. $V_{\text {nominal }}$ represents the rated system voltage.

\section{CASE STUDY}

A field experiment with three scenarios was held in an islanded low voltage network to investigate the impact of DER management actions on the voltage source bus and on current source busses.

The test system is Distributed Energy Resources Test Facility (DER TF) of Ricerca sul Sistema Energetico (RSE) S.p.A. [20]. It is a three phase LV $(400 \mathrm{~V})$ AC distribution network including different types of DERs. The network has islanded operation option with flexibly configurable lines and device connection points. The facility also hosts a LV DC microgrid with NaNiCL batteries and a bi-directional interface converter. All the batteries are connected to the AC feeder through individual inverters. The facility has a central monitoring and control system in which main system parameters can be followed and specific power set points can be sent as commands to each DER inverter individually.

The system is operated in islanded mode by opening the breaker on the feeder, which connects all the devices to the utility and using lithium-ion battery group as the voltage source (Figure 1). Two of the battery groups (lead-acid and $\mathrm{NaNiCl}$ batteries) are considered as grid-following units, while the programmable load is included in the scenario to load the system.

In the first test scenario, the grid-forming unit power output was increased by loading the device (with programmable load) to observe the changes in its terminal voltage. The results are provided in Figure 2. As can be seen from the figure, the main unit was loaded with $1.22 \mathrm{~kW}$ at first, causing its terminal voltage to drop from $400 \mathrm{~V}$ to $398.5 \mathrm{~V}$. The load was increased in seven steps up to $7.4 \mathrm{~kW}$ and the terminal voltage of the master unit dropped down to $391.1 \mathrm{~V}$. In summary, the terminal voltage of the master unit was decreased by $1.84 \%$ in response to $6.1 \mathrm{~kW}$ increase in the device active power output. The slope of the curve given in Figure 2 was calculated as $1.2 \mathrm{~V} / \mathrm{kW}$.

In the second scenario, the lead-acid battery group and $\mathrm{NaNiCl}$ batteries were managed individually to reduce the loading of the master unit (lithium-ion battery group). Management accuracy of each controlled device is given in Table I. In this test scenario, DERs with inverters in current source mode provided above 94\% management accuracy.

In the third scenario, the changes in the voltage of the master unit bus and the furthest node of the feeder are observed in response to certain power set point commands sent to inverters of current source DERs ( $\mathrm{NaNiCl}$ battery and lead-acid battery) in two control steps. On the other hand, lithium-ion battery, as the master unit, changed its power output according to supply/demand gap of the system, while maintaining the voltage in operational limits. Figure 3 shows the voltage values for each of the control steps, while Figure 4 has the power output values for the two managed battery groups (the $\mathrm{NaNiCl}$ battery and the lead-acid battery) and the voltage source of the microgrid (the lithium-ion battery).

As can be observed from Fig. 3 and 4, voltage of the $\mathrm{NaNiCl}$ battery group located at the far end of the feeder is highly dependent on the power exchange of that node with the rest of the system. In the second control step, even though voltage of both lithium-ion and lead-acid battery busses increased due to a reduction in the power output of lithium-ion battery, voltage of the $\mathrm{NaNiCl}$ battery bus reduced because of the decrease in the power supplied by the $\mathrm{NaNiCl}$ battery to the system. It is due to the nature of current controlled mode of inverters, in which the device needs to increase or decrease its terminal voltage to supply a desired amount of power to the system.

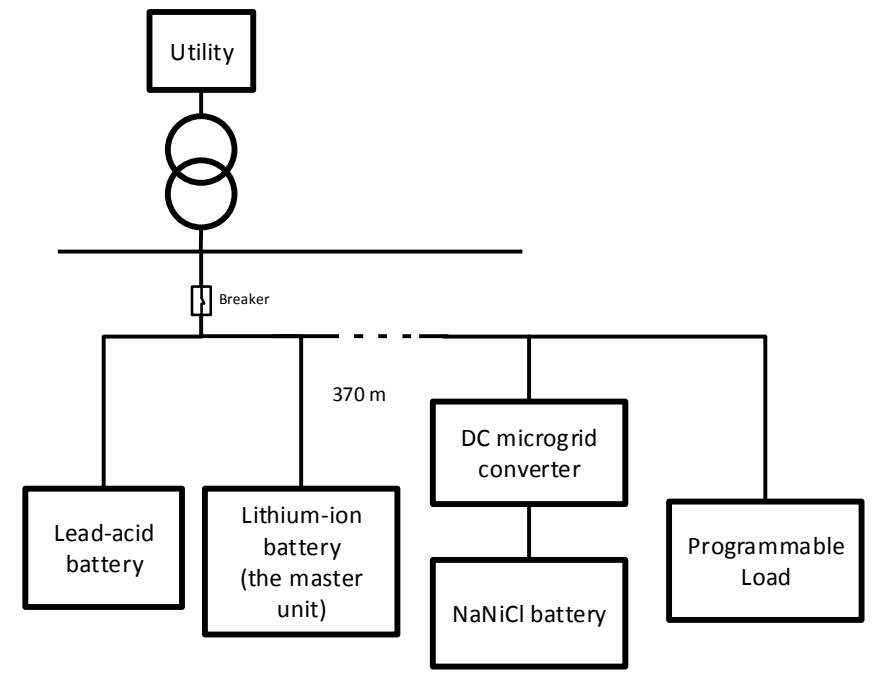

Fig. 1. Islanded operation test setup

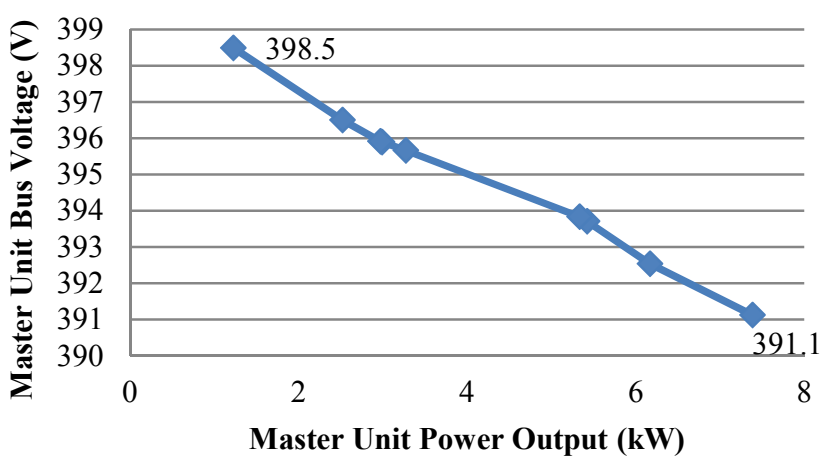

Fig. 2. Change of the master unit (lithium-ion battery group) output voltage according to power output 
TABLE I. Management Performance of Devices IN IsLANDED OPERATION

\begin{tabular}{|c|c|c|}
\hline $\begin{array}{c}\text { Controlled } \\
\text { Device }\end{array}$ & $\begin{array}{c}\text { Maximum } \\
\text { Managed } \\
\text { Power (kW)/ } \\
\text { Management } \\
\text { Target } \\
\text { (kW) }\end{array}$ & $\begin{array}{c}\text { Management } \\
\text { Accuracy } \\
(\%)\end{array}$ \\
\hline $\begin{array}{c}\text { Lead-acid } \\
\text { battery } \\
\text { group }\end{array}$ & $7.27 / 7.50$ & 96 \\
\hline $\begin{array}{c}\text { NaNiCl } \\
\text { batteries }\end{array}$ & $7.88 / 7.50$ & 94 \\
\hline
\end{tabular}

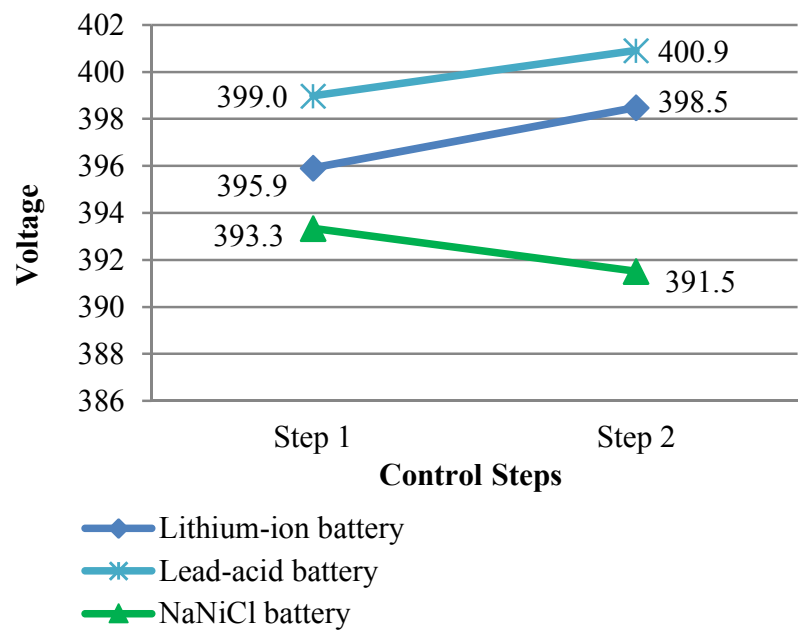

Fig. 3. Voltage profile of the devices for the two tested control steps

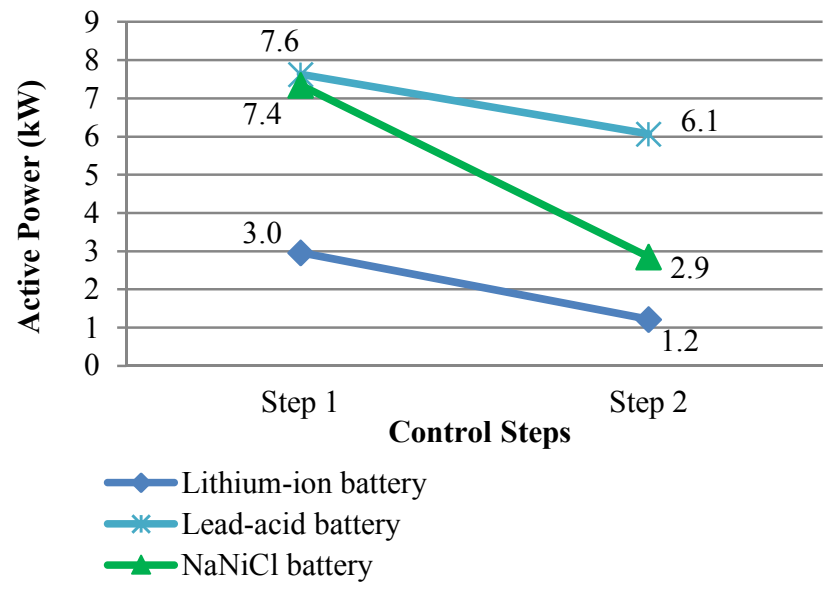

Fig. 4. Power output of the devices for the two tested control steps

The achievable corrective impacts of managed devices on bus voltages compared to the values for the same amount of managed active power in grid-connected operation are provided in Table 2 .
TABLE II. MANAgEMENT PERFoRmanCE OF DEVICES IN ISLANDED OPERATION

\begin{tabular}{|c|c|c|c|}
\hline \multirow{2}{*}{$\begin{array}{c}\text { Controlled } \\
\text { Device }\end{array}$} & $\begin{array}{c}\text { Managed } \\
\text { Power } \\
\mathbf{( \% )}\end{array}$ & \multicolumn{2}{|c|}{$\begin{array}{c}\text { Corrective Impact on Device } \\
\text { Bus Voltage } \\
\text { (\%) }\end{array}$} \\
\cline { 3 - 4 } & $\begin{array}{c}\text { In Grid- } \\
\text { connected } \\
\text { Operation }\end{array}$ & $\begin{array}{c}\text { In Islanded } \\
\text { Operation }\end{array}$ \\
\hline $\begin{array}{c}\text { Lead-acid } \\
\text { battery } \\
\text { group }\end{array}$ & 7.27 & 0.79 & 1.34 \\
\hline $\begin{array}{c}\text { NaNiCl } \\
\text { batteries }\end{array}$ & 7.88 & 0.84 & 1.56 \\
\hline
\end{tabular}

\section{CONCLUSION}

Field tests showed that, DER management is more effective at improving the voltage profile in islanded operation, since the voltage source as a battery group is more resistant to supply/demand changes in the system. It can be summarized that devices located at the far nodes of islanded feeders are capable of both mitigating localized voltage issues and improving the steady state error of voltage source of the islanded grid. On the other hand, the devices that are located near voltage sources busses can reduce the loading and improve the voltage profile of voltage source busses. In addition to voltage profile improvement, supply/demand balance becomes more crucial to prevent overloading of the voltage source asset and possible blackouts in islanded operation. Over $94 \%$ management accuracy observed in the field test provides a promising potential for supply/demand balancing in such systems.

The future work is planned to be on development and testing of approaches for active prosumer integration into DER power and energy management activities through a combination of real-time monitoring and data processing techniques with gamification [21-22].

\section{ACKNOWLEDGEMENT}

This research has been performed using the ERIGrid Research Infrastructure and is part of a project that has received funding from the European Union's Horizon 2020 Research and Innovation Programme under the Grant Agreement No. 654113. The support of the European Research Infrastructure ERIGrid and its partner RSE S.p.A. is very much appreciated.

The authors wish to acknowledge financial support provided under the framework of ERA-Net Smart Grids Plus by "The Scientific and Technological Research Council of Turkey (TUBITAK)" from Turkey and "The Foundation of Science and Technology (FCT)" from Portugal.

\section{REFERENCES}

[1] L. Schwartz, M. Wei, W. Morrow, J. Deason, S. R. Schiller, G. Leventis et. al. (2017, January). Electricity end uses, energy efficiency, and distributed energy resources baseline: Distributed Energy Resources Chapter. [Online]. Available: 
https://energy.gov/sites/prod/files/2017/02/f34/Electricity\%20E nd\%20Uses\%2C\%20Energy\%20Efficiency\%2C\%20and\%20Di stributed $\% 20$ Energy\%20Resources.pdf

[2] S. Bacha, D. Picaul, B. Burger, I. Etxeberria-Otadui and J. Martin, "Photovoltaics in Microgrids: An Overview of Grid Integration and Energy Management Aspects," IEEE Industrial Electronics Magazine, vol. 9, issue 1, pp. 33-46, March 2015.

[3] J. L. Paternina, L. Contreras and E. R. Trujillo, "Study of Voltage Stability in a Distribution Network by Integrating Distributed Energy Resources into a Virtual Power Plant," Contemporary Engineering Sciences, vol. 10, no. 29, pp. 1441-1455, January 2017.

[4] O. Palizban, K. Kauhaniemi and J. M. Guerrero, "Microgrids in active network management-Part I: Hierarchical control, energy storage, virtual power plants, and market participation," Renewable and Sustainable Energy Reviews, vol. 36, pp. 428439, August 2014.

[5] A. Venkataraman, S. Dutta, Y. Li, S. Kayal, L. M. Costa, T. Jiang et. al., "Development of a Power Mix Management System for REIDS Microgrids," in Asian Conference on Energy, Power and Transportation Electrification (ACEPT) 2016, pp. 1-5.

[6] R. Zhao, X. Zhang, P. Li, K. Wang, M. Xue and C. Wang, "Optimal sizing, operating strategy and operational experience of a stand-alone microgrid on Dongfushan Island," Applied Energy, vol. 113, pp. 1656-1666, January 2014.

[7] B. M. Eid, N. A. Rahim, J. Selvaraj and A. H. E. Khateb, "Control Methods and Objectives for Electronically Coupled Distributed Energy Resources in Microgrids: A Review," IEEE Systems Journal, vol. 10, no. 2, pp. 446-458, June 2016.

[8] J. Rocabert, A. Luna, F. Blaabjerg and P. Rodriguez, "Control of Power Converters in AC Microgrids," IEEE Transactions on Power Electronics, vol. 27, no. 11, pp. 4734-4749, November 2012.

[9] P. Basak, S. Chowdhury, S. Halder nee Dey and S. P. Chowdhury, "A literature review on integration of distributed energy resources in the perspective of control, protection and stability of microgrid," Renewable and Sustainable Energy Reviews, vol. 16, issue 8, pp. 5545-5556, October 2012.

[10] J. M. Guerrero, P. C. Loh, T. L. Lee and M. Chandorkar, "Advanced Control Architectures for Intelligent MicrogridsPart II: Power Quality, Energy Storage, and AC/DC Microgrids," IEEE Transactions on Industrial Electronics, vol. 60, no. 4, pp. 1263-1270, April 2013.

[11] A. Bidram, A. Davoudi, F. L. Lewis and J. M. Guerrero, "Distributed Cooperative Secondary Control of Microgrids Using Feedback Linearization," IEEE Transactions on Power Systems, vol. 28, no. 3, pp. 3462-3470, August 2013.
[12] Q. Shafiee, J. M. Guerrero and C. Vasquez, "Distributed Secondary Control for Islanded Microgrids-A Novel Approach," IEEE Transactions on Power Electronics, vol. 29, no. 2, pp. 1018-1031, February 2014.

[13] A. Bidram and A. Davoudi, "Hierarchical Structure of Microgrids Control System," IEEE Transactions on Smart Grids, vol. 3, no. 4, pp. 1963-1976, December 2012.

[14] L. Meng, E. R. Sanseverino, A. Luna, T. Dragicevic, J. C. Vasquez and J. M. Guerrero, "Microgrid supervisory controllers and energy management systems: A literature review," Renewable and Sustainable Energy Reviews, vol. 60, pp. 12631273, July 2016.

[15] J. Y. Kim, J. H. Jeon, S. K. Kim, C. Cho, J. H. Park, H. M. Kim et. al., "Cooperative Control Strategy of Energy Storage System and Microsources for Stabilizing the Microgrid during Islanded Operation," IEEE Transactions on Power Electronics, vol. 25, no. 12, pp. 3037-3048, December 2010.

[16] J. Kim, S. K. Kim and J. H. Jeon, "Coordinated State-of-Charge Control Strategy for Microgrid during Islanded Operation," in $3^{r d}$ IEEE International Symposium on Power Electronics for Distributed Generation Systems (PEDG) 2012, pp. 1-7.

[17] A. Choudar, D. Boukhetala, S. Barkat and J. M. Brucker, "A local energy management of a hybrid PV-storage based distributed generation for microgrids," Energy Conversion and Management, vol. 90, pp. 21-33, January 2015.

[18] M. G. Ippolito, M. L. Di Silvestre, E. R. Sanseverino, G. Zizzo and G. Graditi, "A local energy management of a hybrid PVstorage based distributed generation for microgrids," Energy, vol. 64, pp. 648-662, January 2014.

[19] S. H. Park, J. Y. Choi and D. J. Won, "Cooperative Control between the Distributed Energy Resources in AC/DC Hybrid Microgrid," in IEEE PES Innovative Smart Grid Technologies Conference (ISGT) 2014, pp. 1-5.

[20] F. D'Agostino, S. Massucco, F. Silvestro, C. Bossi, A. Guagliardi, C. Sandroni, "Implementation of a distribution state estimation algorithm on a low voltage test facility with distributed energy resources," in IEEE PES Innovative Smart Grid Technologies Conference Europe (ISGT-Europe) 2016, pp. 1-6.

[21] M. A. Zehir, S. Erpaytoncu, E. Yilmaz, D Balci, A. Batman, M. Bagriyanik et. al., "Analysis of consumer expectations, preferences and concerns on deployment of demand response in Turkey," in $10^{\text {th }}$ International Conference on Electrical and Electronics Engineering (ELECO) 2017, pp. 1262-1266.

[22] A. Barbosa, J. Iría, F. Cassola, A. Coelho, J. Portela, U. Kucuk et. al., "GReSBAS project: A gamified approach to promote more energy efficient behaviours in buildings," in $10^{\text {th }}$ International Conference on Electrical and Electronics Engineering (ELECO) 2017, pp. 1258-1261. 